\title{
Analyzing the role of Bavan Valley in Mamasani as tourists attraction
}

\author{
Mohammad Ali Firoozi $^{\mathrm{a}}$, Majid goodarzi ${ }^{\mathbf{b}^{*}}$ and Abdolmotalleb Akbari ${ }^{\mathrm{c}}$
}

${ }^{a}$ Associate Professor of Geography and Urban Planning, Shahid Chamran University, Ahwaz, Iran

${ }^{b}$ Ph.D Student of Geography and Urban Planning, university of Isfahan ,Isfahan, Iran

${ }^{c}$ MA in Geography and Urban Planning, Rezvanshahr Sadoogh Payam nor University, Yazd, Iran

ARTICLEINFO ABSTRACT

Article history:

Received April 28, 2012

Accepted 22 July 2012

Available online

July 262012

Keywords:

Ecotourism

Tourism development

Bavan Valley

Janat-e-Arba'e (four paradises)

SWOT

\begin{abstract}
Tourism industry plays an important role on developing economy especially in regions where there are different historical, landscape and other natural attractions. Bavan Valley located in Nur Abad Mamasani city in Iran is one of the well-known places among tourists. The region has outstanding natural landscapes, moderate weather especially in spring and summer, low distance from the major road locating between different local regions such as Fars, Bushehr, Khuzestan, and Kohkiluye Boyer Ahmad Province. These regions provide appropriate accessibility for the citizens of highly populated cities of this province and it plays essential role of a major attractive pole in southern part of the country. The primary objective of this research is to recognize the present barriers for attracting tourists and to analyze the tourists' satisfactions associated with the facilities and tourist services. The statistical population of this research includes all the tourists of Bavan Valley in which 381 individuals were chosen as the sample of this research, using Cochran's formula. The results indicate that there is a significant relationship between the absence of advertisement about Bavan Valley and the number of tourists in this zone $(\mathrm{P}<0.05)$. The findings also show that there is a significant relationship between lack of infrastructural equipments and un-development in tourism industry $(\mathrm{P}<0.05)$. Moreover, the findings of SWOT analysis indicates that 9 internal strength versus 10 internal weaknesses and 7 external chance versus 8 external threat were recognized and analyzed with regard to ecotourism in this zone. Thus, generally 16 strength and chances as the advantages and 18 weaknesses and threats as the obstacles about the Bavan Valley's tourism were recognized in order to develop tourism.
\end{abstract}

\section{Introduction}

During the past few years, there have been increasing interests in tourism industry. In many countries, especially developing countries, tourism development is closely related with competitiveness and attractiveness of tourist destinations. Therefore, identification of tourism potentials has direct relationship with the need of achieving destination competitiveness on tourist market. A successful tourism industry is accomplished using an appropriate strategic planning. 
Korunovski and Marinoski (2012) studied a specific kind of tourism associated with cultural heritage through the analysis of the key components that define it. They focused on a specific area through which it highlights its applicative value. The first part generates a broader context in which cultural tourism should be a part of the tourist opportunities. The second part considers a specific tourist destination, the city of Ohrid, which defines the necessary activities to ensure successful development of the cultural tourism. The analysis is based on the application of the strength, weakness, opportunities and threats (SWOT) methodology, used for the wider area of Macedonia, with a detailed case study elaboration for the Ohrid area as suitable for development of cultural tourism. Strength, weakness, opportunities, threats (SWOT) is considered as one of the most popular methods for analysis a business unit. Strategic planning using strength, weakness, opportunities and threats (SWOT) has become very popular methods among many practitioners (Burkart \& Medlik, 1989; Show \& Williams, 1994; Valentin, 2001; Dyson, 2004; Ahmed et al., 2006; Wehring, 2006). Korunovski and Marinoski (2012) differentiated the basic areas such as the supply side, the scope of governance, marketing and promotion, with different indicated activities necessary to ensure the sustainable development of cultural tourism in an area protected by UNESCO. Generally, it must be noted that if cultural tourism is a complex kind of tourism, then for its development the cluster approach must be essential which will ensure involvement of all stakeholders.

Zhang (2012) explained that rural tourism could make full use of tourism resources in rural areas to optimize rural industrial structures, extend the agricultural industrial chain. It should also develop rural tourism services, promote nonagricultural employment, increase the incomes of farmers, and create a better economic base for the new rural construction. Zhang (2012) implemented the method of SWOT analysis to make a comprehensive evaluation and analysis on SWOT in the development of rural tourism in Suzhou. Through the combination of internal resources and external environment, Zhang determined the advantages and disadvantages of Suzhou rural resources, comprehends the opportunities and challenges to be faced, and proposed the corresponding countermeasures.

Despite that fact that SWOT has a simple infrastructure, it helps discovering many issues related to business units. Yu and Huimin (2005), for instance, studied hotel reform in China by performing a SWOT analysis. Tsang and Qu (2000) investigated service quality in China's hotel industry in a perspective from tourists and hotel managers. Bernrioder (2002) performed an empirical work on factors in SWOT analysis applied to micro, small-to-medium, and large software enterprises for some United states case study. Sariisik et al. (2011) studied how to manage yacht tourism in Turkey using SWOT analysis and associated strategies. Incaz and Guler (2000) studied important conditions and problems of Turkish Yacht tourism. Ibrahim (2009) investigated tourism development and the environment on the Egyptian red sea coast.

The present study attempts to analyze the role of Bavan Strait of Mamasani, which is considered as one of the quadruplet paradises in tourist attractions, using SWOT model and proposes some strategies for better usage of this incredible attraction.

\section{The proposed study}

Noorabad Mamasani Township is one of the townships of Iran, which is located on the northwest of Fars province between circuits of 50 degrees, 45 minutes to 52 degrees and 10 minutes of east longitude and 29 degrees and 37 minutes to 30 degrees and 41 minutes of north latitude. This township has boundaries with Yasooj township in Kohgiluye and Boyerahmad province from north and northwest, with Kazeroon Borazjan and Bandar-e Genave Townships from south and south west, and from east and north east with Shiraz and Sepidan. Fig. 1 shows details of the region. 


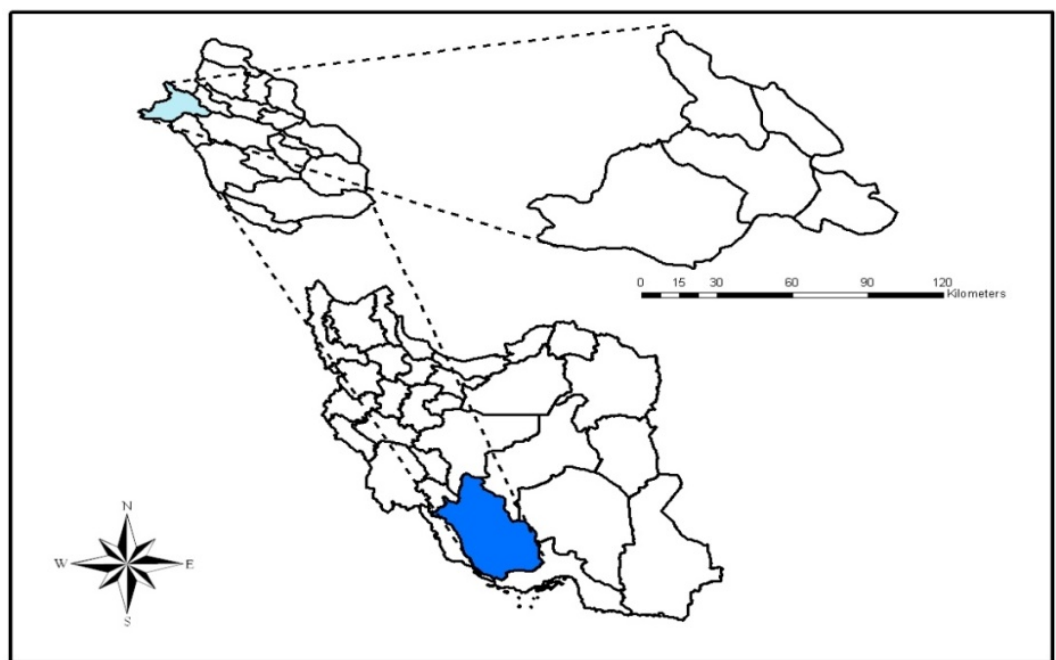

Fig. 1. Spatial location map of Mamasani township in Fars province and Iran

The present study tries to detect important barriers in tourism industry. We also plan to measure the amount of satisfaction among tourists on provided equipments and services in this region. We also propose some strategies for the optimum usage of this natural attraction. The following hypotheses are associated with the proposed study of this paper.

\subsection{Hypotheses}

1. There is a correlation between the lack of advertisement and the number of the tourists in this region.

2. There is a correlation between the shortage of fundamental equipments and non-development of the tourism industry in this region.

The method of this research is a combination of descriptive, documentary and analytic methods that a part of the data is collected through survey. The population of the study includes all tourists who visit Bavan Strait based on the report published by cultural heritage organization, handcraft, and tourism on 50 thousand people visit this place. Substituting this figure in Cochran formula presented here, the sample for questioning was achieved as 381 .

$$
n=\frac{\frac{t^{2} p q}{d^{2}}}{1+\frac{1}{N}\left(\frac{t^{2} p q}{d^{2}}-1\right)}=381 \quad n=\frac{\frac{(1.96)^{2}(.5 * .5)}{(.05)^{2}}}{1+\frac{1}{50000}\left(\frac{(1.96)^{2}(.5 * .5)}{(.05)^{2}}-1\right)} \approx 381
$$

$$
\mathrm{t}=1.96 \quad \mathrm{p}=0.5 \quad \mathrm{q}=0.5 \quad \mathrm{~d}=0.05 \quad \mathrm{~N}=50000
$$

Data instruments are based on library, documentary, questionnaire and utilizing the resources from the related organizations. Cronbach alpha was achieved as 0.95 , which shows the reliability of the study. Data analysis has been carried out in two levels of descriptive and inferential statistics. In the level of descriptive statistics with the usage of statistic indices such as frequency, percent and mean for data analysis and statistic tests, Chi-square test was used.

\section{Bavan Valley}

There is a green and pleasing village which is six kilometer far from the west part of Noorabbad between two mountain ranges that has been called Bavan from ancient times. Twenty current springs towards Giblah with various pomegranate, walnut, fig gardens and different interconnected trees that 
provided shadow for it, gave a special position to this region (Khormai, 2007) so that geographers and scholars say that embellishments and beauties of the world are four things: Bavan valley, Ghoote Dameshgh, Saghd-e Samarghand and Marghzar-e Shidan.

Bavan valley has embraced one of the four beautiful gardens of the world. Its products were adorning the kings' table. The talented poets, each one by a different description has talked about the blooming condition of these orchards. Ibn-e Balkhi asserts that (from the beginning to the end of the valley, length and width, all is gardens of fruit so that sun could not shine to the earth and there is fruit from all kinds). He also mentions the mosque of Bavan in his description and says: Bavan is a town that has a grand mosque and pulpit. Bavan has been taken into account in all historical periods and it has been considered as one of the quadruplet paradises of the world. This valley is most beautiful natural landscapes in Mamasani and Fars province which is 6 kilometers far from the west of Noorabad.

\section{Research findings}

In order to generalize the results from the sample to the population, we test the research hypotheses. In this research, in order to determine the existence or the lack of existence of significant correlation between the variables, the univariate non-parametric test of chi-square is used.

Hypothesis 1: It seems that there is a significant correlation between the lack of advertisement and the number of the tourists in this region. According to the fact that hypothesis 1 is a combination of two variables and on the other hand, because we do not have real dependent variable in this research that could be data given, then, in order to analyze the hypotheses the non-parametric test of chi-square was used. The first hypothesis which is a combination of two variables, after the logical sum of them and dividing them by numbers ranging from 1 to 5 the result was like Likert Scale. Therefore, after carrying out this operation through non-parametric test of chi-square, this hypothesis was analyzed that its results are presented bellow.

\section{Table 1}

The observed and expected frequency related to the first hypothesis

\begin{tabular}{llll}
\hline Indices' dimensions & Observed N & Expected N & Residual \\
\hline Very low & 58 & 95.3 & -37.3 \\
Low & 236 & 95.3 & 140.8 \\
average & 70 & 95.3 & -25.3 \\
High & 17 & 95.3 & -78.3 \\
\hline Total & 381 & & \\
\hline
\end{tabular}

Chi-squared for the observation given in Table 1 is equal to 293.530 and the level of significance was 0.000. Therefore, the null hypothesis is rejected, which means there is a significant correlation between the lack of advertisement and the number of the tourists in this region.

Hypothesis 2: There is a significant relationship between the shortages of fundamental facilities and non-development of tourism industry in this region.

\section{Table 2}

The observed and expected frequency related to hypothesis 2

\begin{tabular}{llll}
\hline Indices' dimensions & Observed N & Expected N & Residual \\
\hline Very low & 50 & 76.2 & -26.2 \\
Low & 118 & 76.2 & 41.8 \\
average & 106 & 76.2 & 29.8 \\
High & 72 & 76.2 & -4.2 \\
Very high & 35 & 76.2 & -41.2 \\
\hline Total & 381 & & \\
\hline
\end{tabular}


Similarly, we repeat the same Chi-square test for the second hypothesis of this research and the results are summarized in Table 2. Chi-squared for the observation given in Table 2 is equal to 293.530 and the level of significance was 0.000. Therefore, the null hypothesis is rejected, which means there is a significant relationship between the shortages of fundamental facilities and nondevelopment of tourism industry in this region.

\section{SWOT analysis}

\subsection{The effective internal factors on tourism in the region}

The purpose of this stage is to evaluate internal environment of the region in order to recognize the strength and weakness points, that is, the aspects that are appropriate or preventive should be considered in achieving the planning goals and accomplishing their tasks. Therefore, in this part, three categories of existing strategies, reactions and resources are examined and they are divided under the title of strength and weakness points in the framework of tourism development.

\subsection{The effective external factors on tourism in the region}

The aim of this step is to find the effects of the external environment in the studied region for recognizing the threats and opportunities that the region is encountered with improvement of the tourism. Therefore, according to the conducted studies and examining the conditions of the environment of the region, the total of opportunities, the existing and effective threats on this region are examined and they are considered in terms of tourism aspect in the framework of development dimensions of tourism.

\section{Table 3}

The system of evaluation analysis of the tourism indices in Bavan Valley based on SWOT model

\begin{tabular}{|c|c|c|c|}
\hline Thre & es & ss & \\
\hline $\begin{array}{l}\text {-pollutants from industry and } \\
\text { life centers } \\
\text {-development of building } \\
\text { activities as a competitor for } \\
\text { attracting the investment in } \\
\text { tourism industry } \\
\text { The lack of enough health } \\
\text { centers in the region } \\
\text {-loss of trees and plant coverage } \\
\text { and its destructive effects such } \\
\text { as increase of flood and } \\
\text { destruction of agricultural lands } \\
\text {-loss of traditional and local } \\
\text { culture (such as language, local } \\
\text { customs and clothing etc. ) with } \\
\text { increase in the number of } \\
\text { tourists } \\
\text {-increase of social violations } \\
\text { with the entrance of tourists in } \\
\text { this region than before } \\
\text {-centralized tourism attractions } \\
\text { in some neighbor cities and } \\
\text { provinces }\end{array}$ & $\begin{array}{l}\text {-plans of environment protection } \\
\text { agency in maintaining the natural } \\
\text { resources } \\
\text {-cabinet decisions for creating } \\
\text { residential centers in different } \\
\text { levels } \\
\text {-the increase of government } \\
\text { attention towards the planning and } \\
\text { investing in tourism } \\
\text {-increase of private section } \\
\text { motivation in investment in this } \\
\text { area } \\
\text {-association with development } \\
\text { plans in tourism of the neighbor } \\
\text { cities and provinces } \\
\text {-presence of native authorities in } \\
\text { different managing positions of } \\
\text { the province with a complete } \\
\text { knowledge about the region and its } \\
\text { competence } \\
\text {-being near the main road, at the } \\
\text { center of four provinces of fars, } \\
\text { Bushehr, Khuzestan and Kohgiluye } \\
\text { and Boyerahmad }\end{array}$ & $\begin{array}{l}\text { gion } \\
\text { lestaurants } \\
\text { tourism with different reasons } \\
\text { icrease of land trade and lack of } \\
\text { e about tourism industry etc. } \\
\text { planning and governmental } \\
\text { and unsuitability of the } \\
\text { infrastructures (such as roads } \\
\text { ge) } \\
\text { facilities and equipments in } \\
\text { he region views between some } \\
\text { ejudices } \\
\text { and difference between the } \\
\text { the tourists and the people of } \\
\text { riate distribution of the tourists } \\
\text { nt seasons (reduction in winter) }\end{array}$ & $\begin{array}{l}\text {-Moderate climate in different seasons } \\
\text {-springs (such as mineral } \\
\text { springs) and various falls } \\
\text {-existence of mountainous } \\
\text { habitats in the region with } \\
\text { specific species of animals } \\
\text { - forest habitats in the studied } \\
\text { region } \\
\text {-Having the feature of tourist } \\
\text { attraction and hospitality of the } \\
\text { settlers } \\
\text {-beautiful and unique landscapes } \\
\text { with green areas and gardens in } \\
\text { the region } \\
\text {-the existence of heights and } \\
\text { peaks for doing sports such as } \\
\text { mountain climbing and hiking } \\
\text {-easy availability to this region } \\
\text { for tourists quiet environment and } \\
\text {-Having quist } \\
\text { without noise specially for } \\
\text { taking rest, relaxation and } \\
\text { recreation }\end{array}$ \\
\hline
\end{tabular}

As indicated in Table 3, the internal weakness and strength points in the studied region, external opportunities and threats regarding recognition of tourism were studied. Therefore, in a simple analysis and conclusion one can say that the threshold of vulnerability of Bavan Valley regarding tourism is very high. The objective of this paper is to perform demands revision and proposing suitable politics for removing the weaknesses and threats using the strong points and opportunities. 


\section{Table 4}

Systematic analysis of the strategies and tourism in Bavan Valley based on the model SWOT

Subject

Spatial structure and system of Bavan Valley tourism

Spatial structure and system of Bavan Valley tourism

\begin{tabular}{|c|c|}
\hline $\begin{array}{l}\text { Strategy } \\
\text { of strong } \\
\text { points } \\
\text { (SO) }\end{array}$ & $\begin{array}{l}\text {-Advertisement for introducing the studied } \\
\text { region } \\
\text {-Using experts and native people to make } \\
\text { plans for the region } \\
\text {-revision of the way of distribution of the } \\
\text { equipments, services and facilities of } \\
\text { tourism and prioritizing the re-allocation } \\
\text { of this equipments to the touristic regions } \\
\text { with high and average capability } \\
\text {-Beside the planning method and } \\
\text { government support from the touristic } \\
\text { regions, logical exploitation from } \\
\text { institutions, supportive rules and } \\
\text { regulations for development and } \\
\text { equipping the infrastructures and different } \\
\text { facilities of tourism in the region should } \\
\text { be accomplished } \\
\text {-revision and expansion of the related } \\
\text { institutions and organizations of the region } \\
\text { for training people and tourists for } \\
\text { optimum and desirable usage of the region }\end{array}$ \\
\hline
\end{tabular}

Strategy

of making

minimum

of

weakness

points

(ST)
-Government inclination to tourism as tourism capability in making income

-education and providing the the needs of the region for reduction of using the forests and pastures

-preventing the pollution of water and soil resources

-establishing health centres

-making various attractions for attracting the tourists

- training people to have suitable behaviour with tourists

-preparation and encouragement of people to participate in development of infrastructures, equipments and facilities of tourism and having income through this way and also participating the private section in the fields that people could not participate

-holding seminars by the related organizations for developing the tourism in the region

-constituting special rules and regulations for optimum usage of the region and tourism products and also prevention of destruction and pollution of this resources -maintaining the beautiful nature of Bavan Valley with plan and noticing on principles of sustainable development

-improvement of the roads leading to Bavan Valley and installation of traffic signs

-increasing the security of the region by establishing tourism police

- using the potentials of the region for removing the poverty and unemployment in the region

Strategy of investment of private section

opportunities Protection and preservation of the forest

(WO) habitats and animal species in the region

- increasing the motivation of travelling in urbanization classes

- recognition and exploitation of the attractions, products and other relative advantages of tourism

-using expertise and experienced workforce in order to create cooperative organizations and also promoting tourism training through meetings with people

-Creating harmony between the institutions and different sections related to tourism

- creating residential centres in the region -appropriate creation and distribution of the restaurants in the region and supervising their quality

- proposing the facilities to the private section for investment in the region

-Government investment in tourism section -Providing recreational and sport facilities -Making culture by the related organizations for maintaining the natural environment

-Attention to the roads and installation of traffic signs

Strategy of -Development and improvement agricultural threat tourism for suitable exploitation the avoidance landscapes, farms and gardens of the region for (WT) income and preventing the destruction of the farms and plant coverage -Exploiting organizational competence, rules and regulations for reducing the dangers and ecological and environmental pollutions in the studied region

-Providing security of the region in order to prevent the social violations and other crimes -Give variety to the equipments, activities and tourism services in order to attract the attention of the tourists and consequently, increase the number of the tourists 
to ecotourism in this zone. Thus, generally 16 strength and chances as the advantages and 18 weaknesses and threats as the obstacles about the Bavan Valley's tourism were recognized in order to develop tourism.

We can conclude that the vulnerability level of this zone is high with regard to ecotourism and it actually needs reviewing and presenting some policies for removing the weaknesses and threats using strength and chances. Finally, according to the investigations and analyses carried out, it could be concluded that organizational and structural, socio-cultural, market, educational obstacles as well as lack of professional labor force, weakness in presenting information, lack of governmental planning and investing, etc were recognized as difficulties of developing the tourist industry in this area.

\section{Conclusion}

In this paper, we have presented an empirical study to determine strength, weakness, opportunities and threats for one of the most beautiful regions of Iran for developing tourism industry. The proposed model designed a questionnaire and distributed among 384 randomly selected out of 50,000 visitors in Bavan Valley. The proposed study of this paper considered two hypotheses, where the first one considered whether there was a correlation between the lack of advertisement and the number of tourists in the region and the second hypothesis was associated with the relationship between the shortage of fundamental equipments and non-development of tourism industry. The results of Chisquare tests confirmed both hypotheses. Next, we have accomplished SWOT analysis and determined all issued associated with that region.

\section{Acknowledgment}

The authors would like to thank the anonymous referees for constructive comments on earlier version of this paper.

\section{References}

Ahmed, A.M., \& Zairi, M., \& Almarri, K.S. (2006). SWOT analysis for Air China performance and its experience with quality. Benchmarking: An International Journal, 13(1/2), 160-173.

Bernrioder, E. (2002). Factors in SWOT analysis applied to micro, small-to-medium, and large software enterprises: an Austrian study. European Management Journal, 20(5), 562-73.

Burkart, A., \& Medlik, S. (1989). Tourism, Past, Present and Future. $2^{\text {nd }}$ ed., London Heineman.

Dyson, R.G. (2004). Strategic development and SWOT analysis at the University of Warwick. European Journal of Operational Research, 15(3), 631-40.

Ibrahim, Z. (2009). Tourism development and the environment on the Egyptian red sea coast. Unpublished Dissertation for the degree of Master of Environmental Studies in Geography, Waterloo, Ontario, Canada.

Incaz, G.S., \& Guler, N. (2000). The conditions and problems of Turkish Yacht tourism. International Conference on Maritime Engineering and Ports, 2, Barcelona, 231-239.

Khormaie, M. K. (2007). Fars Tourism Guidebook. $1^{\text {st }}$ ed., Shiraz: Pars culture Press.

Korunovski, S., \& Marinoski, N. (2012). Cultural Tourism in Ohrid as a Selective form of Tourism

Development. Procedia - Social and Behavioral Sciences, 44, 104-113

Sariisik, M., Turkay, O., \& Akova, O. (2011). How to manage yacht tourism in Turkey: A SWOT analysis and related strategies. Procedia Social and Behavioral Sciences, 24, 1014-1025.

Show, G., \& Williams, A.M. (1994). Critical Issue in Tourism. Blackwell: Oxford UK and Cambridge USA.

Tsang, N., \& Qu, H. (2000). Service quality in China's hotel industry: a perspective from tourists and hotel managers. International Journal of Contemporary Hospitality Management, 12(5), 316-26. 
Valentin, E.K. (2001). SWOT analysis from a resource-based view. Journal of Marketing Theory and Practice, 9(2), 54-69.

Wehring, O. (2006). Growing Argentina's wine industry - a SWOT analysis. available at: justdrinks.com (Management Briefing) (accessed May 28, 2009).

Yu, L., \& Huimin, G. (2005). Hotel reform in China: a SWOT analysis. Cornell Hotel \& Restaurant Administration Quarterly, 46(2), 153-169.

Zhang, X. (2012). Research on the development strategies of rural tourism in Suzhou based on SWOT analysis. Energy Procedia, 16(B), 1295-1299 